\title{
Paradoxical Worsening of Ocular Symptoms after Spontaneous Closure of a Carotid Cavernous Fistula: Case Report
}

\author{
L. Fernando Gonzalez, MD \\ Thomas Jefferson University \\ Jurij R. Bilyk, MD \\ Wills Eye Institute \\ Pascal Jabbour, MD \\ Thomas Jefferson University
}

Stavropoula Tjoumakaris, MD

Thomas Jefferson University

Aaron S. Dumont, MD

Thomas Jefferson University

Follow this and additional works at: https://jdc.jefferson.edu/jhnj

Let us know how access to this document benefits you
see nextpage for additional autinors

\section{Recommended Citation}

Gonzalez, MD, L. Fernando; Bilyk, MD, Jurij R.; Jabbour, MD, Pascal; Tjoumakaris, MD, Stavropoula; Dumont, MD, Aaron S.; Chalouhi, MD, Nohra; and Rosenwasser MD, Robert H. (2012) "Paradoxical Worsening of Ocular Symptoms after Spontaneous Closure of a Carotid Cavernous Fistula: Case Report," JHN Journal: Vol. 7 : Iss. 1 , Article 3.

DOI: https://doi.org/10.29046/JHNJ.007.1.006

Available at: https://jdc.jefferson.edu/jhnj/vol7/iss1/3

This Article is brought to you for free and open access by the Jefferson Digital Commons. The Jefferson Digital Commons is a service of Thomas Jefferson University's Center for Teaching and Learning (CTL). The Commons is a showcase for Jefferson books and journals, peer-reviewed scholarly publications, unique historical collections from the University archives, and teaching tools. The Jefferson Digital Commons allows researchers and interested readers anywhere in the world to learn about and keep up to date with Jefferson scholarship. This article has been accepted for inclusion in JHN Journal by an authorized administrator of the Jefferson Digital Commons. For more information, please contact: JeffersonDigitalCommons@jefferson.edu. 


\section{Paradoxical Worsening of Ocular Symptoms after Spontaneous Closure of a Carotid Cavernous Fistula: Case Report}

\section{Authors}

L. Fernando Gonzalez, MD; Jurij R. Bilyk, MD; Pascal Jabbour, MD; Stavropoula Tjoumakaris, MD; Aaron S. Dumont, MD; Nohra Chalouhi, MD; and Robert H. Rosenwasser MD 


\section{Paradoxical Worsening of Ocular} Symptoms after Spontaneous Closure of a Carotid Cavernous Fistula: Case Report

L. Fernando Gonzalez, MD'; Jurij R. Bilyk, MD²; Pascal Jabbour, MD'; Stavropoula Tjoumakaris, MD'; Aaron S. Dumont, MD'; Nohra Chalouhi, MD' Robert H. Rosenwasser, MD ${ }^{1}$

${ }^{1}$ Neurosurgery Department, Thomas Jefferson
${ }^{2}$ Wills Eye Institute, Philadelphia, Pennsylvania
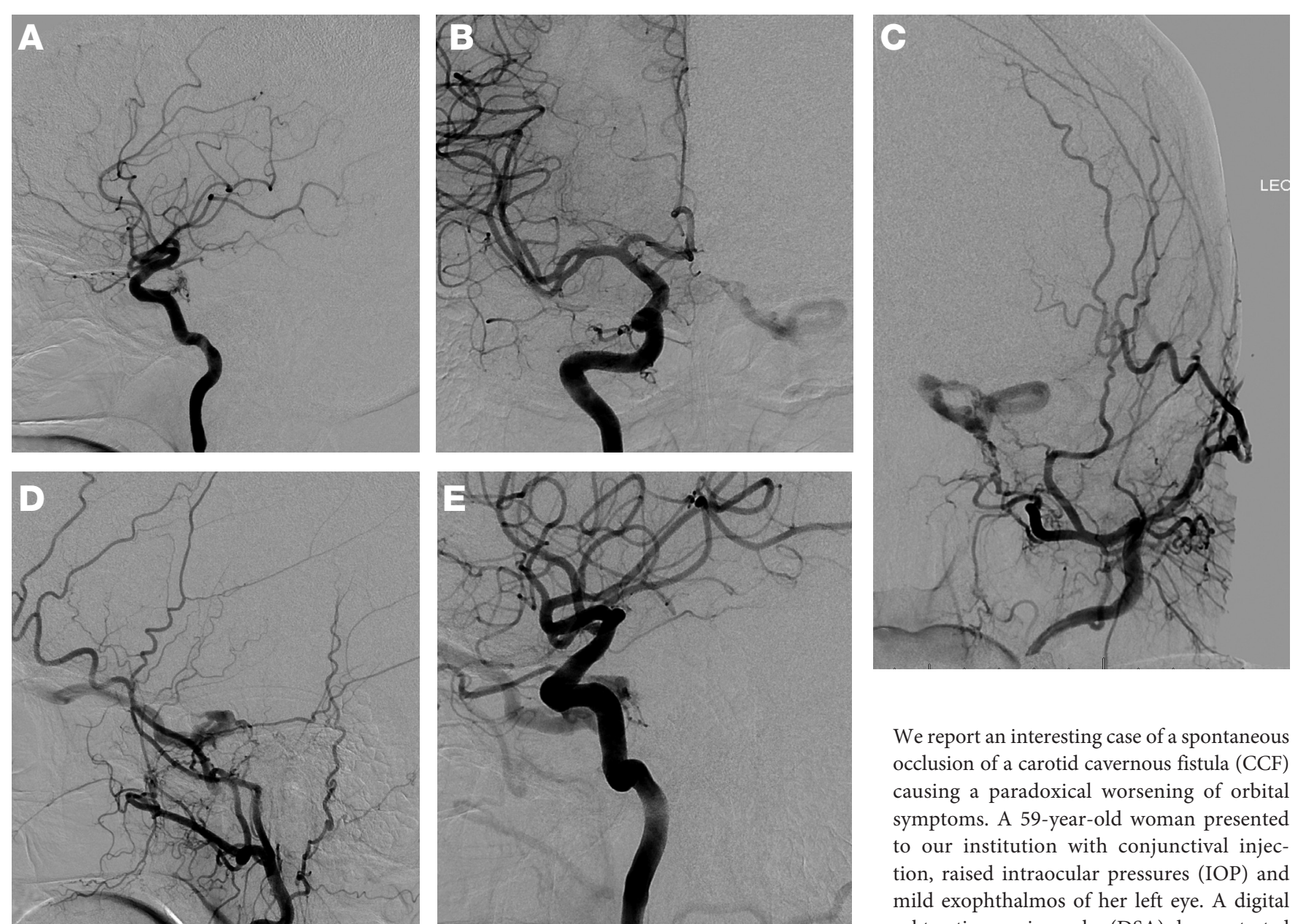

Figure 1

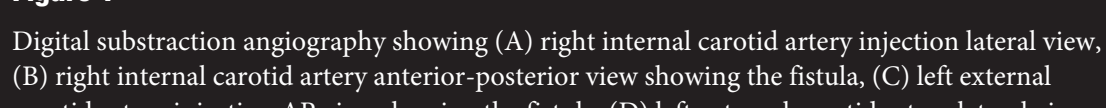

(B) right internal carotid artery anterior-posterior view showing the fistula, (C) left external
carotid artery injection AP view showing the fistula, (D) left external carotid artery lateral view

showing a prominent superior orbital vein, $(\mathrm{E})$ left internal carotid artery injection showing
fistula and a large superior ophthalmic vein treatment with a 3 -stents telescoping technique. Note the straightening of the vessel with stent placement

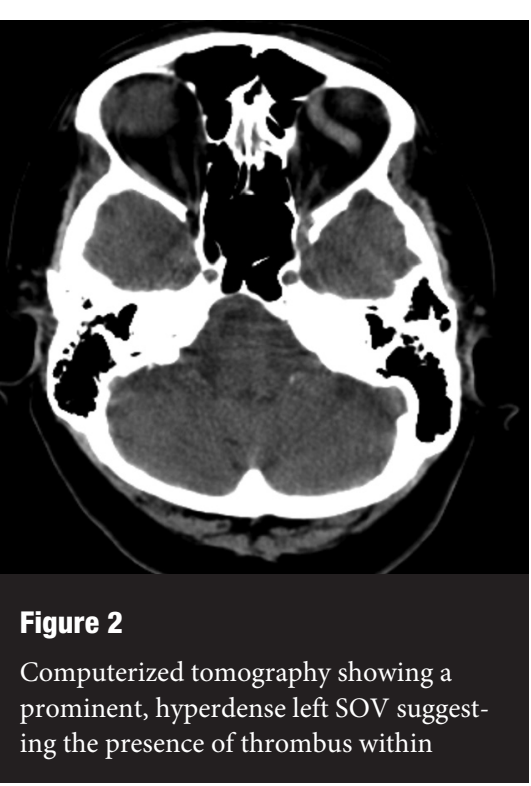

improvement and her IOP were within normal improvement and her IOP were within normal
limits. Spontaneous thrombosis of the SOV can trigger the obliteration of a CCF with possible paradoxical worsening of orbital symptoms.
DSA is the gold standard of diagnosis and management is directed toward decreasing IOP Introduction

We present an interesting case of a type-D spontaneouly with a provicat closed of the symptoms due to thrombosis of the superior ophthalmic vein (SOV). The authors also give directives for the management of these extremely rare cases.

Case Report

A 59 year-old female presented with conjunctival injection associated with elevated intraocular pressures (IOP) in the left eye medications. She initially presented about one year earlier to her local ophthalmologist, who eventually referred the patient to a glaucoma specialist for unilateral IOP elevatio and a progressive supetior arcuate defect on automated perred to a neuro ophthel palient was then management. Visual acuity was 20/25 in each eye and mild left exophthalmos was present. A two prism diopter esotropia with a limited a dith with a left abducens nerve paresis. An enlarge the superomedial eyelid skin. Funduscopic examination, demonstrated increased cupping

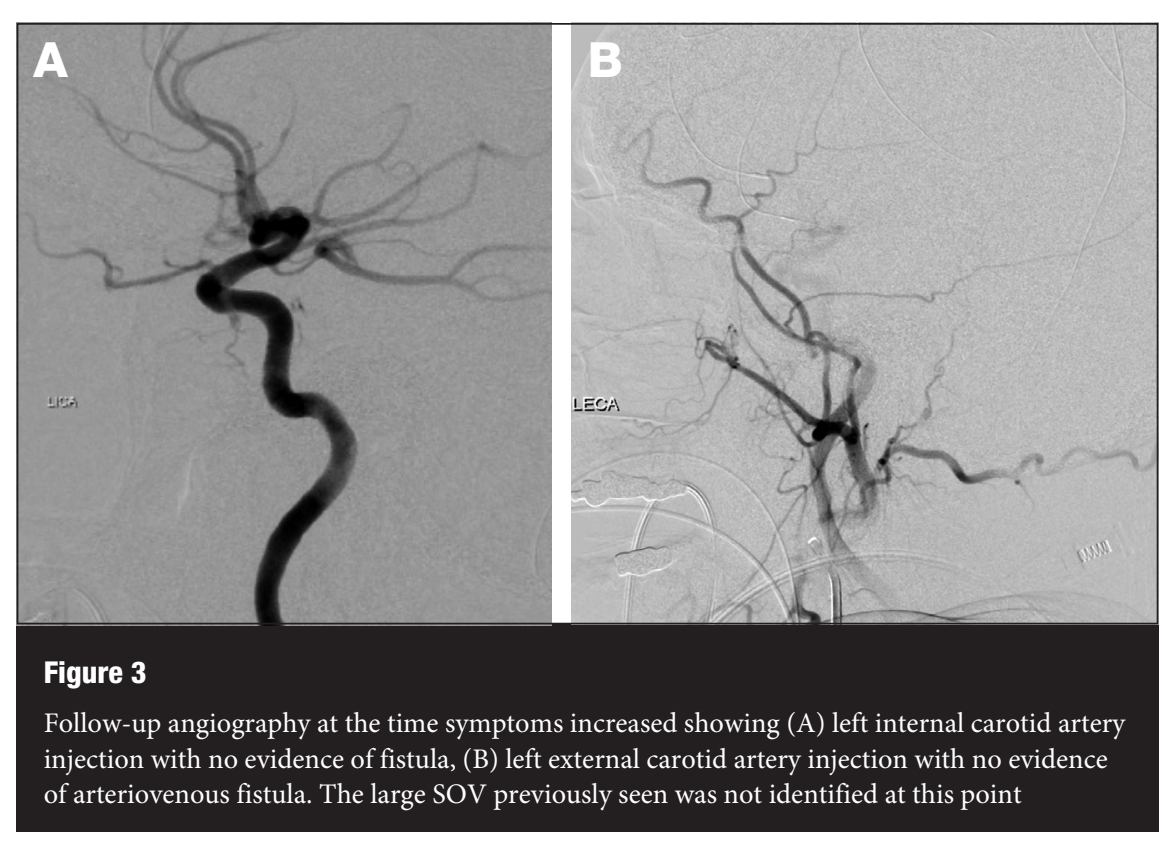

on the left side and thinning of the retinal nerve fiber layer was confirmed on ocular coherence tomography.

MRI of the head showed a dilated left SOV, exophthalmos, and an enlarged cavernous

(DSA) A digital subtraction angiography SOV with feeders from both the internal and external carotid arteries bilaterally (Figure 1), but predominately on the left side, consistent with a type-D lesion. ${ }^{3}$ Endovascular
was offered but the patient declined. Fifteen months later, the patient presented with an acute exacerbation of her scleral injection, proptosis, and ocular pain, which occurre pun left eye associated with an elevated IOP of 45 $\mathrm{mm} \mathrm{Hg}$, a left afferent pupillary defect, mild ptosis, external ophthalmoplegia, and upper eyelid edema with minimal ecchymosis. Computerized tomography showed a prominent, presence of thrombus within the vein (Fisure 2). A DSA, including both internal, external, and vertebral arteries, showed no evidence of arteriovenous fistula and no visualization of the (GRE) (Figure 4) mixed signal with hyperintensity alo on the left side consistent with intravenous thrombosis. Following DSA, IOP progressively decreased from 45 to $18 \mathrm{~mm} \mathrm{Hg}$ without any
changes to the topical glaucoma regimen and

the afferent purillyry defect resolved over be next 24 hours. The external ophthalmoplegia and conjunctival injection persisted, but there
was a marked improvement of exophthalmos and periocular pain. On subsequent follow-up two weeks later, a subtle left arcuate defect was $20 \mathrm{~mm} \mathrm{Hg}$

Discussion

We present a case of a wonge with elevated IOP, conjunctival injection, optic neuropathy, and a documented CCF on initial cerebral angiography who then spontaneously obliter列 venous drins in the presence of cortical become significant, such as elevated intraocular pressure, decreased visual acuity, optic neuropathy, or external ophthalmoplegia. Multiple 作 spe Spontaneous resolution of arteriovenous mala few case reports in the literature, wost has hemorrhagic presentation 1.5 In Abdulrauf $\mathrm{s}^{1}$ series a single vein was a common finding in $83 \%$ of their patients with spontaneous thrombosis. The proposed mechanism is a thromboembolic not been proven histologically? 
Resolution of CCFs has been reported after angiography, where a clot developed during the sibly occluding the arteriovenous connection in a similar mechanism as just described. Similar
events have been described soon after gamm events have been described soon after gamma
knife radiotherapy, also potentially secondary knife radiotherapy, ${ }^{8}$ also potentially secondary
to a thromboembolic event from the angiogram to a thromboembolic event from the angiogran used during the treatment pla
from an acute radiation effect.

Bujak et a $1^{4}$ reported 2 patients with dural CCF causing severe clinical manif that spontaneously resolved before endovascular intervention. Unlike the present case, obliteration of the CCF was associated with symptoms. Sergott and colleagues ${ }^{10}$ reported thrombosis of the $\mathrm{SOV}$ with an acute worsening of symptoms. In contrast to our case, however, thrombosis of the SOV in these 2 patients was not associated with an obliteration of the fistula acute worsening in the orbital signs and symptoms caused by a spontaneous thrombosis of the SOV and an angiographically documented complete cure of the CCF. Acute thrombosis of SOV with probable extension proximally into the cavernous sinus accounted for the resolu-
tion of the CCF. Since the SOV provides the major and in many cases only venous outflow for the orbit, sudden worsening of orbital congestion manifests as an orbital compartment syndrome (OCS). In addition, since the may occur in an anterograde fashion from the SOV to the facial venous system and inferiorly through connections with the pterygopalatine venous plexus, even with an active CCF. Sudden thrombosis of the SOV may temporarily blo

Thrombosis of the SOV in all likelihood results cavernous sinus, precipitating the occlusion of the CCF; slow flow triggers the coagulation cascade, manifesting as thrombosis. Based on anatomic studies, the SOV in this particular case was the single major venous drainage for elevation from decreased episcleral ven outflow, and a congestive optic neuropathy. Once there is no visualization of the CCF on DSA, the endovascular options are limited.
Despite the presence of severe orbital signs, the management of the OCS may be difficult. In edly improving within 48 hours. ${ }^{10}$ The goal of

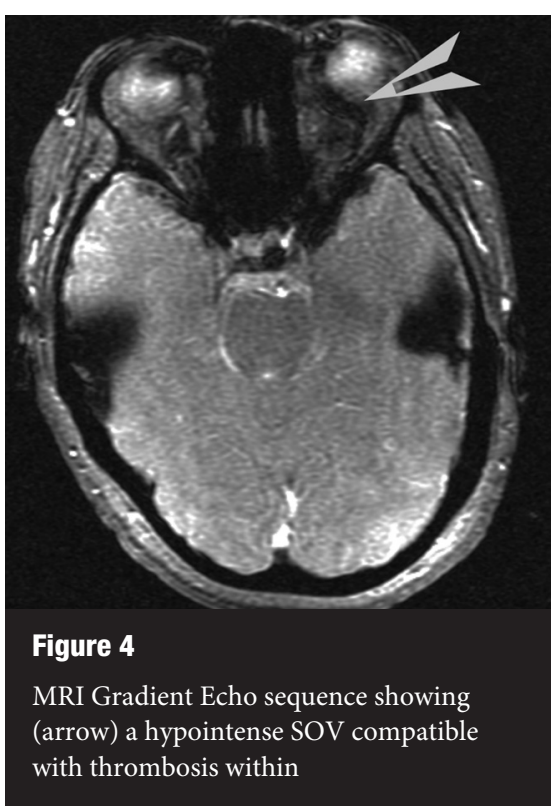

OCS therapy in such situations is to "buy time" until orbital congestion resolves. Presumably age pathways during this time. Initilly, dopical anti-glaucoma medications are intityted apica with intravenous mannitol. If this fails, a lateral canthotomy with cantholysis is performed, bu even this may provide only temporary relief, since the OCS will recur as orbital sof tisse Worsening of the orbital and ocular symp-
toms does not always represent persistence progression of the arterio-venous fistula as in this case illustrates. In cases of presumed spontaneous SOV thrombosis, the use of DSA has been questioned, ${ }^{10}$ since the diagnosis of SOV the MRI signal be made wist Mic. However, evolve over time ${ }^{6}$ and mast pret accurately in the SOV. The clinician is then left in a quandry of "waiting out" a possible thrombosis and delaying DSA or proceeding with timely DSA to confirm thrombosis or treat DSA, we support the use of this modality in all cases of acute worsening of orbital signs, since spontaneous SOV thrombosis is a rare event, and delay in definitive care in the face of an acute, severe OCs may result in perno of cons

Conclusions

aradoxical worsening of ocular symptoms is extremely rare and posibly trigeced by thrombosis of the SOV. Although DSA is the gold standard for diagnosis, there is no role for focused on managing the acute orbitopathy and raised intraocular pressure.

References

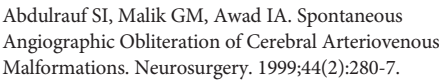

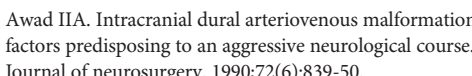

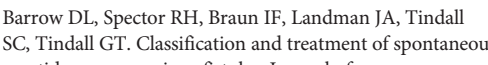

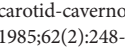

Suliak M, Margolin E, Thompson A, Trobe ID. Spontaneou
iesolution of

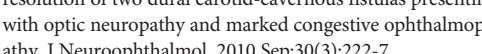

Ollice MMD, D'Aliberti GMD, Arena OMDD, Sclain CM

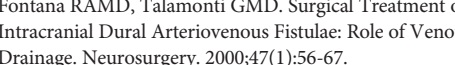

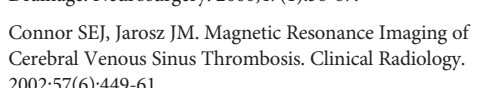

Eurra MMD, Kagawa SMD. Spontaneous Disappearance of
Huge Cerebral Arteriovenous Malformation: Case Report

Lau LL, Wu HM, Wang AG, Yen MY, Hsu WM. Paradoxic
torsening with

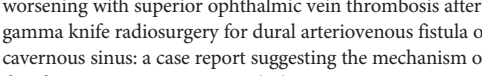

the phenomenonn. Eye. 2006;20(12): 1426-8

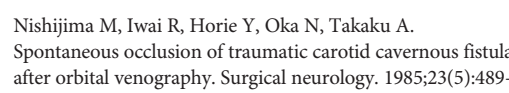

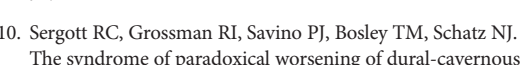

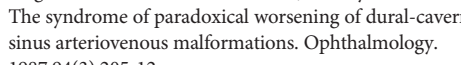

\section{Complications of Decompressive Craniectomy}

Sandra Ho, BS'; Yinn Cher Ooi, MD2; Muhamad Adil Sheikh, MBBS3; Mitchell Maltenfort, $\mathrm{PhD}^{4}$. Jack Jallo MD, $\mathrm{PhD}$

IJefferson Medical College, Philadelelphia, Pennsylvania
2Neurosurgery Department, ULCA L Los Angeles, Calformi

${ }^{3}$ Dow Medical College, Karachi, Pakistan

${ }^{4}$ Rothman Institute, Philadelphia, Pennsylvania
5 Neurosurgery Department, Thomas Jefferson University, Philadelphia, Pennsylvania

\section{Introduction}

Persistent elevation of intracranial pressure (ICP), if untreated, may lead to brain ischemia or lack of without any signs of improvement decompressive craniectomy can be an effective alternative solution. ${ }^{71}$

Decompressive craniectomies (DC) have been used as a method of controlling intracranial pressure
in patients with cerebral edema secondary to cerebral ischemia, subarachnoid hemorrhage (SAH), and traumatic brain injury (TBI), among others. ${ }^{8}{ }^{8.1}$ Several studies over the years have demonstrated the efficacy of hit $p$ is effective first tier treatment for intractable interceranial pressure due to the rudimentary neurologica There itself 13 -18 The majority of these studies only investigated the impact of this procedure in patiene with traumatic brain injury. The purpose of this study is to investigate the rates of various complications associated with the decompressive craniectomy procedure in patients that did not suffer from traumatic brain injury, and to determine whether the same associations between preoperative

Methods

A retrospective review of a prospectively collected data set of patients who had a decompresA ef decoct measured by Glasgow coma scale (GCS) at discharge, time period between craniectomy and cranioplasty and type of flap used for cranioplasty. Rates of various complications were tabulated and we investigated the association of several patient parameters with patient outcome, and rates of the

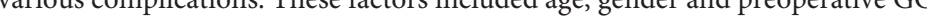
Appropriate statistical tests were used to determine the strength of associations; Spearman's $\mathrm{p}$,
Student's $\mathrm{t}$-test and multivariate regression were performed using the JMP statistical package (version 7.02: SAS Institute, Cary NC).

Results

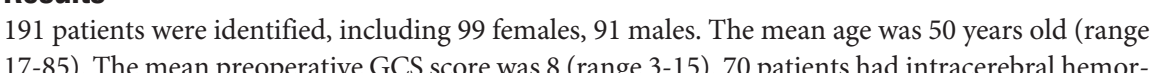
rhage (36 mo 60 had revalive brain surgery (11\%), 15 had stroke $(78 \%), 11$ had closed head trauma $(5.7 \%), 4$ had thrombosed aneurysm $(2.1 \%), 3$ had ruptured arteriovenous malformation (AVM) $(1.6 \%), 2$ had penetrating trauma $(1.4 \%), 1$ had tumor $(0.5 \%)$, and 3 were unreported $(1.6 \%)$. A bifrontal craniectomy was performed on 4 cases $(2.1 \%)$ and 187 were unilateral craniectomies $(97.9 \%)$. The incidences
101 of the 191 patients (53\%) had at least one complication. 42 patients died despite the procedure. Of the survivors $(\mathrm{n}=149)$, a significant
number were discharged to rehabilitation $(\mathrm{n}=121), 8$ were discharged to full time nursing facilities, 2 remained in the hospital, 1 was dis$(n=13)$. Three cases did not report discharge destination. There was no correlation between age and mortality

19 patients had a preoperative GCS score ranging from $^{3-5,49}$ patients ranged from 6-9 a a postoperative GCS score of 6 pe patients had ween $6-9$ and 68 patients had scores greater han 9. Mean postoperative GCS scores were $3.87 \pm 0.49 \quad($ mean $\pm \mathrm{SE})$ above preoperative (C)S scores. Patients with higher pre-op GCS upon dider age tended to have higher GCS and patients that had one or more complica作 $(\mathrm{p}<0.037, \mathrm{p}<0.016)$. Neither gender nor age

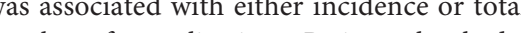

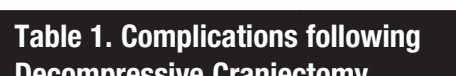

\begin{tabular}{|l|l|}
\hline \multicolumn{2}{|l|}{ Decompressive Craniectomy } \\
\hline Complication & N (\%) \\
\hline Hydrocephalus & $55(28.7)$ \\
\hline VP shunt & $37(19.4)$ \\
\hline Herniation & $40(20.9)$ \\
\hline Vasospasm & $10(5.2)$ \\
\hline Subdural hygroma & $18(9.4)$ \\
\hline Seizures & $2(1)$ \\
\hline Sunken flap & $2(1)$ \\
\hline Flap resorption & 0 \\
\hline Increased ICP & $9(4.7)$ \\
\hline Infection & $42(21.9)$ \\
\hline $\begin{array}{l}\text { *Pneumonia was the commonest infection in } \\
\text { this study }\end{array}$ \\
\hline
\end{tabular}

this study 